\title{
INVESTIDURA, PROGRAMACIÓN Y DIRECCIÓN POLÍTICA
}

\author{
JUAN LUIS PÉREZ FRANCESCH \\ Profesor Titular de Derecho Constitucional \\ Universidad Autónoma de Barcelona
}




\section{SUMARIO}

El Gobierno como órgano de diRección política en el MarCo del Sistema parlamentario español. La investidura del Presidente del Gobierno como PRESUPUESTO DESENCADENANTE DE LA DIRECCIÓN POLITICA GUBERNAMENTAL. NOTA BiBLIOGRÁFICA. 


\title{
INVESTIDURA, PROGRAMACIÓN Y DIRECCIÓN POLÍTICA
}

\author{
POR \\ JUAN LUIS PÉREZ FRANCESCH \\ Profesor Titular de Derecho Constitucional \\ Universidad Autónoma de Barcelona
}

\section{EL GOBIERNO COMO ÓRGANO DE DIRECCIÓN POLÍTICA EN EL MARCO DEL SISTEMA PARLAMENTARIO ESPAÑOL}

El artículo 97 CE configura al Gobierno como un órgano constitucional encargado de la dirección política del Estado. En su primer párrafo indica que aquél "dirige la política interior y exterior, la Administración civil y militar y la defensa del Estado".

Esta competencia de dirección política se ejerce en el marco de una estructura de parlamentarismo racionalizado y en el seno de un Estado social y democrático de Derecho, aspectos ambos que determinarán la posición constitucional del Gobierno, de manera que resultará insuficiente su configuración como mero poder ejecutivo. Por el contrario, el Gobierno se nos presenta como un auténtico director de la política estatal, que influye en la composición y funcionamiento de otros órganos constitucionales, especialmente las Cortes Generales, cuyo producto típico, la ley vendrá, así, determinado en gran medida por el papel directivo del Gobierno. Paralelamente, hay que destacar que esa dirección política debe ser aprehendida por el intérprete como una manifestación de la normatividad constitucional, de lo que se deduce que el artículo $97 \mathrm{CE}$ indica el "status" que le corresponde al Gobierno, pero los exponentes concretos de aquella dirección 
habrá que rastrearlos a lo largo de todo el texto constitucional y tendrá su prolongación en otros sectores inferiores del ordenamiento jurídico. Especialmente deberemos atender al concreto reparto competencial entre Estado y Comunidades Autónomas, para delimitar claramente la competencia directiva de los diferentes órganos colegiados en sus diferentes esferas de actuación.

Ciñéndonos ahora al Gobierno central, para comprender el peso específico del Gobierno en el sistema constitucional español hemos de superar una visión excesivamente estrecha de la legitimidad de los órganos constitucionales, que desborde a las Cortes Generales, y que afecta al Gobierno, especialmente a su Presidente, teniendo un fundamento explícito en el artículo 1.2 CE. No hay que olvidar que en nuestro sistema parlamentario el Gobierno se constituye una vez que el Presidente del mismo ha obtenido la confianza parlamentaria del Congreso de los Diputados por medio del voto de investidura (cfr. arts. 99 y $113 \mathrm{CE}$ ). A partir de ese dato, el Presidente del Gobierno, que además viene configurado como director de la acción del colegio gubernamental y coordinador de la actividad de sus miembros (art. 98.2 CE), será quien goce de auténtico protagonismo a la hora de definir la orientación del Gobierno, concretando y desarrollando el programa político que expuso en su día al recibir la investidura.

Debemos, pues, matizar la afirmación de que el Gobierno dirige la política, desde el reconocimiento de su estructura y funcionamiento internos, en los que, sin perjuicio de su carácter colegiado, destaca la preeminencia del Presidente. Es así, la Constitución asigna determinadas competencias específicamente al Presidente (p. ej. presentación de un recurso de inconstitucionalidad o de una cuestión de confianza) y otras al órgano colegiado (aprobación de un proyecto de ley o ejercicio de la potestad reglamentaria).

Debemos también atender al apoyo explícito de la mayoría parlamentaria al programa político gubernamental, y no sólo en el momento inicial de la investidura sino también a lo largo de la legislatura, ejerciendo una función de mantenimiento, de impulso y de control. La doctrina italiana ha reflexionado especialmente sobre este extremo acuñando la expresión «indirizzo político» en la que se ha querido reivindicar una cierta "centralidad» del Parlamento, a pesar de la tantas veces comentada crisis del mismo, incapaz de hacer frente a las exigencias que impone el intervencionismo estatal.

Ahora bien, el estudio de la competencia de dirección política gubernamental puede hacerse, en mi opinión, desde dos grandes puntos de vista. Un primero, que parta del análisis de los órganos constitucionales y de sus competencias respectivas y otro, que responda a una perspectiva más 
"politológica» y que se base en la existencia dentro del régimen parlamentario de una mayoría parlamentaria-gubernamental. Pienso que una perspectiva de Derecho Constitucional no puede perder de vista la configuración concreta del ámbito competencial de los diferentes órganos, aunque puede apoyarse en una óptica como la segunda de las citadas en aras de una explicación realista del funcionamiento práctico del sistema parlamentario. De esta manera, la "mayoría política", de especial trascendencia en el parlamentarismo mayoritario (Lijphart) forma un bloque cohesionado que se dedicará a dirigir la política del Estado, articulando así la «colaboración de poderes». En esta variante del sistema parlamentario (España, 1982, 1986 y 1989), como recuerda Molas, el cuerpo electoral designa de hecho en un mismo acto a todo un conjunto de personas para desarrollar un programa político y un líder que lo dirija, el futuro Presidente del Gobierno. Por ello podemos hablar de un régimen de Canciller o de Primer Ministro. En este contexto, se ha considerado que mayoria parlamentaria-gubernamental y oposición devienen los polos en que realmente y al margen de una división orgánica se estructura hoy el principio de la división de poderes, en un sistema regido por la regla de la mayoría y abierto al pluralismo.

Junto a este punto de vista metodológico deberíamos traer a colación una percepción que MIRKINE-GUETZEVICH ya planteó en los años veinte: la incorrección de concebir el parlamentarismo como un instrumento de lucha contra el Gobierno, sosteniendo una colaboración entre ambos porque los dos son órganos que emanan del pueblo, puesto que han sido elegidos tanto uno como el otro para la realización de un programa electoral, en el desarrollo del cual el Gobierno cumple un papel predominante.

Apreciaciones como las citadas, siempre que no nos hagan olvidar la regulación jurídico-formal de las relaciones interorgánicas y de las competencias que la Constitución atribuye a cada órgano, nos pueden ilustrar enormemente sobre el sentido de la competencia gubernamental de dirección política que el artículo $97 \mathrm{CE}$ asigna al Gobierno.

Es precisamente en el ejercicio de la potestad legislativa del Estado donde se manifiesta más claramente la dirección política gubernamental, porque si bien en nuestra Constitución proliferan las reservas de ley como atributo formal de las Cortes Generales, como indica PÉREZ ROYO, hoy quien realmente legisla es el Gobierno, limitándose el Parlamento ha corregir las iniciativas gubernamentales, siendo por consiguiente dificultoso impedir la realización efectiva de dicha iniciativa, es decir, su plasmación en ley formal. Hemos de admitir, por tanto, que la relación entre Parlamento y Gobierno ha sufrido un notorio cambio si lo comparamos con el esquema del 
parlamentarismo clásico. Hoy no cabe concebir al Gobierno como una especie de comité del Parlamento - si es que lo ha sido alguna vez en la práctica- que actúa en su nombre a partir de una habilitación concreta, como sostenía CARRÉ DE MALBERG. Cambio que ha afectado a la posición de la ley en el ordenamiento jurídico, porque no responde a una pretendida voluntad general rousseauniana atravesada por la nota de la armonía social, sino más bien a un interés prevalente que responde a la mayoría política dirigida por el Gobierno, que se impone como tal previa discusión parlamentaria y delimitada formal y materialmente por la Constitución.

\section{LA INVESTIDURA DEL PRESIDENTE DEL GOBIERNO COMO PRESUPUESTO DESENCADENANTE DE LA DIRECCIÓN POLÍTICA GUBERNAMENTAL}

Según el artículo 99 CE el candidato propuesto por el Rey al Congreso de los Diputados para recibir el voto de investidura expondrá el programa político del Gobierno que pretenda formar y solicitará la confianza de la Cámara. De esta manera, la investidura se realiza a favor del futuro Presidente del Gobierno para que éste desarrolle, previa formación del órgano gubernamental, el programa político para el que fue investido.

Esta regulación de la investidura en la Constitución española suscita a nuestro juicio dos cuestiones que trataremos a continuación: el alcance de la investidura y el peso específico que cabe atribuir al programa político gubernamental.

a) El alcance de la investidura: Por medio de ella, el Presidente del Gobierno recibe la confianza del Congreso de los Diputados para llevar a cabo el programa político del Gobierno que pretenda formar a continuación. De esta manera, se observa la preeminencia de aquel en el seno del Gobierno, ya en este momento inicial. Una vez investido es nombrado por el Rey (art. 62.d CE) por medio de Real Decreto refrendado por el Presidente del Congreso de los Diputados (art. 64.1 CE). Posteriormente, se designarán por el Presidente del Gobierno el resto de miembros del órgano gubernamental: formalmente (art. 62.e CE) se nombran y cesan por el Rey por medio de Real Decreto refrendado por el Presidente del Gobierno. Aquí encontramos también su capacidad directiva personal (art. 98.2 CE). 
El Gobierno existe, por tanto, gracias a la investidura de su Presidente y del mismo modo deberá dimitir cuando el Congreso le obligue a ello, por medio de los instrumentos de exigencia de responsabilidad política, el triunfo de una moción de censura (art. $113 \mathrm{CE}$ ) o cuando éste pierda una cuestión de confianza (art. $112 \mathrm{CE}$ ). Pero una vez formado el Gobierno y mientras el Congreso no le deniegue la confianza al Presidente aquel se dedicará a desarrollar el programa político que éste expuso, cuando solicitó la investidura, programa que es, por consiguiente, del Presidente y de todo el Gobierno.

La Constitución española, exige la investidura del Presidente del Gobierno antes de la formación de éste, en línea con la Ley fundamental de Bonn (art. 63), pero el sistema español, desarrollado en los artículos 170 a $172 \mathrm{RCD}$, no coincide con el alemán ni en la constitucionalización del programa político ni en la exigencia de debate. Nada dice, sin embargo, la Constitución ni el Reglamento del Congreso de los Diputados en relación a la composición del futuro Gobierno, por lo que su revelación en este momento procesal podría calificarse todo lo más de un acto de cortesía parlamentaria.

Siguiendo a BAR, podríamos decir que «la investidura no versa tanto sobre la persona del candidato exclusivamente, como sobre el binomio candidato-programa, no pudiendo pronunciarse los diputados separadamente de una cosa u otra. Y es importante destacar esta unión entre estos dos elementos dado que la alteración de uno de ellos, bien sea el candidato, bien su programa político, supone necesariamente un cambio sustancial en el contenido de la propuesta regia». No obstante, nada parece impedir que un mismo candidato se presente con programa diferente una segunda vez, puesto que es precisamente éste el que contextualiza y aglutina el apoyo parlamentario.

Para REVENGA, por medio del binomio candidato-programa viene a suplirse la ausencia de una atribución constitucional expresa en favor del Presidente del Gobierno semejante a la existente en el artículo 95 de la Constitución italiana o del artículo 65 de la Ley Fundamental de Bonn, en el sentido de conferir al Presidente del Consejo o al Canciller Federal la facultad de definir los criterios rectores de la dirección política.

Sin embargo, no son muchos los textos constitucionales que consagran en su articulado la referencia al programa político gubernamental. El art. 63 LFB indica que el Canciller será elegido por la Cámara sin debate previo con lo que no exige la presentación de dicho programa. La Constitución 
portuguesa, sin embargo, desciende a detalle y en el artículo 191 -tras la reforma de 1982- afirma: «En el programa de gobierno constarán las principales orientaciones políticas y medidas a adoptar o a proponer en los diversos campos de la actividad gubernamental" y en el 92 explicita la vinculación de los miembros del Gobierno a su programa. Incluso, antes de la mencionada reforma de 1982, el artículo 191 ligaba el programa de gobierno con el programa de la Constitución, es decir, transformaciones socioeconómicas previstas en numerosas normas programáticas.

b) Naturaleza del programa político gubernamental: El programa político concreta el voto de investidura que recibe el Presidente del Gobierno y condiciona, por tanto, la actividad del Gobierno a su correcto desarrollo a juicio de la Cámara. Se puede configurar, en una primera aproximación, como un compromiso que une al Gobierno, por mediación de su Presidente, con el Congreso de los Diputados e incluso a través de éste, con el cuerpo electoral. La trascendencia del programa político como compromiso se desvela especialmente con ocasión de Gobiernos de coalición, en donde un pacto de este orden incide en el programa de forma notoria, en aspectos como el detalle de los diferentes extremos que lo comprenden, e incluso en Gobiernos monocolores con un apoyo de mayoría relativa donde se puede cuestionar desde una ampia oposición ese programa dificultando su desarrollo.

En cualquier caso, el programa gubernamental no es una mera declaración de intenciones genéricas, sino un conjunto de compromisos concretos, cuya efectividad es ciertamente de difícil exigencia jurídica. Se ha hablado de una especie de "contrato de legislatura", a partir de la experiencia alemana-federal de Gobiernos de coalición, que, aunque jurídicamente tendrían escasa, por no decir nula eficacia, sí que la tendrían políticamente, ya sea por medio de la exigencia de responsabilidad política, ya sea por la vía del seguimiento parlamentario y el compromiso de respaldar las iniciativas del Gobierno en el cumplimiento del programa, garantizándolo a través de la disciplina de voto de los parlamentarios.

Respecto del programa político en sentido estricto, la doctrina dominante en España se decanta por la imposibilidad de obtener una sanción jurídica a su incumplimiento. Así, AGUIAR sostiene el carácter de «acto personalísimo del candidato a Presidente del Gobierno, una declaración de intenciones, cuyo contenido y valor está supeditado a su posición parlamentaria, pero a la que no se le puede asignar ninguna virtualidad jurídica». SATRÚSTEGUI, por su parte, indica que la investidura supone "la adopción de unas orientaciones políticas que han de armonizar y coordinar la acción del ejecutivo y el legislativo». BAR, defiende la concepción de 
que el programa del Gobierno tiene el carácter de pacto o compromiso respecto de la Cámara y en su caso respecto de los partidos integrantes de un Gobierno de coalción. Para REVENGA, consiste en un "desideratum cuya efectividad (es) de imposible exigencia en el plano jurídico debido a la (...) falta de valor substantivo del programa». En la misma línea, GALLEGO ANABITARTE/ MENÉNDEZ REXACH, afirman que el programa no vincula jurídicamente al Presidente ya investido, ni al Gobierno que se constituya bajo su dirección, que podrán adoptar decisiones distintas a las previstas en aquel, sin perjuicio de que puedan motivar la exigencia de responsabilidad política. En consecuencia, la responsabilidad política del Gobierno ante el Congreso no está ligada jurídicamente (aunque sí políticamente) a la observancia del programa, por lo que incluso cabría exigir responsabilidad política a un Gobierno respetuoso con su programa.

Frente a esta opinión, VIVER se decanta por afirmar que estamos ante un tertium genus entre la vinculación jurídica apoyada jurisdiccionalmente y la responsabilidad política ajena al control jurídico. El cumplimiento o no del programa puede llegar a convertirse en un parámetro jurídicamente predeterminado del control sobre los órganos (aduciendo como ejemplo de ello el art. 192 de la Constitución portuguesa que establece que los miembros del Gobierno están vinculados al programa), por lo que en caso de incumplirse naceria la obligación de proponer la reformulación de dicho programa, mediante un debate de política general, la votación de una cuestión de confianza, la disolución de las Cámaras o la presentación de una moción de censura. Sin embargo, pienso que estas consideraciones, sin perjuicio de su valor teórico en aras de reivindicar una coherencia en el funciamiento institucional del Gobierno desde una perspectiva democrática, son de difícil aplicación al sistema político español, donde el programa gubernamental no aparece con aquella consistencia, por lo que si bien puede irse modulando por medio de los instrumentos de relación interorgánica entre Parlamento y Gobierno, débilmente se podrá construir una exigencia jurídico-constitucional de hacerlo.

La doctrina italiana se ha esforzado en atribuir un valor jurídico al programa político del Gobierno. Sus reflexiones, sin embargo, no son automáticamente trasladables al caso español por la razón básica de que el proceso de formación del Gobierno diverge notablemente. En Italia es todo el Gobierno y no sólo su Presidente, el que recibe la confianza parlamentaria - de ambas Cámaras - una vez ha sido nombrado, es decir, inmediatamente después de asumir sus funciones constitucionales. En estas circunstancias, ALBERTO RUSSO se esfuerza por asignar consecuencias jurídicas a la presentación del programa político gubernamental 
ante las Cámaras, caracterizándolo como el primero de los actos de dirección política del Gobierno. Por su parte, MORTATI, MAZZIOTI o CUOCUOLO sostienen la vinculación del Gobierno a su programa, una vez obtenida la confianza parlamentaria, por lo que su incumplimiento propiciaría necesariamente la exigencia de responsabilidad política. Estas reflexiones se mueven, como es obvio, en la experiencia italiana de Gobiernos de coalación donde el cumplimiento del programa asegure su estabilidad y éste tenga posibilidades de desarrollo. Otros autores, como PETRI consideran que el programa político carece de relevancia jurídica y su seguimiento no es algo obligatorio sino una orientación de cara al futuro, necesariamente genérico y susceptible de futuras gradaciones.

Con independencia de la conclusión que adoptemos sobre la naturaleza del programa político gubernamental, a los efectos del estudio de la competencia de dirección política del Gobierno como órgano constitucional en el marco de una estructura de parlamentarismo racionalizado, nos permite obsevar que ésta se realizará para el efectivo desarrollo de aquel, para lo cual tendrá en su mano una serie de instrumentos formales que detalla el texto constitucional. Por lo que respecta a la Constitución española, nos aproxima al protagonismo del Presidente del Gobierno y a su preeminencia en el ejercicio de esa misión directiva que encontramos genéricamente en el artículo $97 \mathrm{CE}$, destacando en relación al programa el hecho de que no puede darse de una vez para siempre, estando por consiguiente sujeto a la posibilidad de remodelaciones $y$, en todo caso, el juicio sobre su incumplimiento se realizará desde criterios políticos que pueden desencadenar controles interorgánicos entre Parlamento y Gobierno, pero sin que ello venga exigido en ningún momento. Ahora bien, en la medida en que el programa gubernamental es básicamente el programa con el que el Presidente del Gobierno ha obtenido la investidura del Congreso de los Diputados y siendo él quien canaliza la responsabilidad solidaria del órgano gubernamental, goza de una facultad directiva en el seno de éste que le permitirá cesar a cualquier otro miembro del Gobierno cuando entienda que no responde a la línea trazada por su programa.

\section{NOTA BIBLIOGRÁFICA}

Sobre el Gobierno como órgano de dirección política véase el planteamiento que lleva a cabo I. DE OTTO: «La posición constitucional del Gobierno», en Documentación Administrativa, n. 188, 1980, págs. 139-182 (reproducido también en BASTIDA, F.; PUNSET, R. y OTTO, I.: Lecciones de Derecho Constitucional, vol. 1. Guiastur, Oviedo, 1980, págs. 335-383. 
La concepción de la dirección política como amplia capacidad de iniciativa en la orientación de la actividad estatal, en LóPEZ GUERRA, L.: "La posición constitucional del Gobierno", en Dirección GeneraL del Servicio Jurídico del Estado, Gobierno y Administración en la Constitución, Instituto de Estudios Fiscales, Madrid, 1988, vol. 1, págs. 17-33. También del mismo autor, «Funciones del Gobierno y dirección política». Documentación Administrativa, n. 215, 1988, págs. 15-40.

La tesis de que los exponentes concretos de esa dirección habrá que rastrearlos a lo largo de todo el texto constitucional, se puede encontrar también en TORRES DEL MORAL, A.: Principios de Derecho Constitucional, Atomo, Madrid, 1988, vol. 2, pág. 203.

Sobre la investidura, seguimos aquí el trabajo de REVENGA, M.: La formación del Gobierno en la Constitución española de 1978, CEC, Madrid, 1988, esp. págs. 158-228.

La doctrina del «indirizzo político", en MARTINES, T.: voz "Indirizzo político", Enciclopedia del Diritto, vol. XXI, 1971, págs. 134 y ss. Cfr. asimismo, MANZELLA, A.: II Parlamento, II Mulino, Bolonia, 1977 y MoRTATI, C.: Istitutzioni di Diritto Pubblico, Cedam, Padua, 1975. Entre la bibliografía española reciente destacamos CANOSA USERA, R.: "La actividad de orientación politica. Su relevancia constitucionalm, Revista de Estudios Políticos, n. 67. 1990, págs. 125-152.

La perspectiva de la acción de gobierno centrada en la mayoría parlamentaria-gubernamental, en MOLAS, I. y PITARCH, I.E.: Las Cortes Generales en el sistema parlamentario de gobierno, Tecnos, Madrid, 1987. También en MOLAS, I.: «La oposición en el parlamentarismo mayoritario", Revista del Centro de Estudios Constitucionales, n. 2. 1989, págs. 47.-64. Sobre el parlamentarismo mayoritario, cfr. LIJPHART, A.: Las democracias contemporáneas, Ariel, Barcelona, 1987.

La cita de MiRkine-Guetzevich, en Nuevas tendencias del Derecho Constitucional, Reus, Madrid, 1934, pág. 202.

La referencia a PÉREz RoYo, en "La distribución de la capacidad normativa entre el Parlamento y el Gobierno", en AA.VV.: El Gobierno en la Constitución Española y en los Estatutos de Autonomía, Diputación de Barcelona, 1985, pág. 90.

La posición de CarRé de Malberg, R.: Contribution a la Théorie Générale de l'Etat, Sirey, París, 1922, vol. 2, págs. 71 y ss.

La citada de BAR, en "Comentario al art. 99", en ALZAGA, O. (dir).: Comentarios a las leyes políticas, Edersa, Madrid, 1985, vol. VIII, pág. 172. Igualmente, del mismo autor: El Presidente del Gobierno en España. Encuadre constitucional y práctica política. Cívitas, Madrid, 1983. Cfr. el libro de ReVENGA, M. citado ut supra, esp. págs. 168-169, donde además se pueden encontrar las referencias a la doctrina italiana expuestas en el texto. También son útiles, Nicolás Muñiz, J.: «Programa político y legislativo del Gobierno. Pacto de coalición y contrato de legislatura»; Documentación Administrativa, n. 188. 1980, págs. 385-413. AGUIAR, L.: «La estructura del proceso de formación del Gobierno. El caso español en el marco del derecho comparado", Revista de Derecho Político, n. 6. 1980, pág. 75. Gallego AnABiTARTE/MENÉndez REXACH, "Comentarios al art. 97 CE", EN Alzaga, O. (dir.), ob. cit., pág. 45. VIVER Pi-SUNYER, C.: "Algunos problemas jurídicos en torno a la actividad de dirección política de los ejecutivos de las Comunidades Autónomas", en AA.VV., El Gobierno en la Constitución y..., cit., supra, págs. 302 y ss. También del mismo autor, más recientemente, «El President de la Generalitat", en Comentaris a l'Estatut d'Autonomia de Catalunya, Institut d'Estudis Autonòmics, Barcelona, 1988, pág. 315. 